\title{
Dairy Cow Preferences for Soft or Hard Flooring when Standing or Walking
}

\author{
E. Telezhenko, ${ }^{* 1}$ L. Lidfors, ${ }^{*}$ and C. Bergsten ${ }^{*} \dagger$ \\ *Department of Animal Environment and Health, Swedish University of Agricultural Science, Skara, Sweden \\ †Swedish Dairy Association, Box 234, 53223 Skara, Sweden
}

\begin{abstract}
Concrete is the most commonly used alley flooring in confined dairy herds because of its qualities of construction and ease of cleaning. Nevertheless, the hardness, abrasiveness, and slipperiness of concrete floors have adverse effects on animal well-being and health, and yielding rubber flooring is becoming popular as a way of improving the flooring conditions on walkways. The aim of this study was to investigate preferences of dairy cows for rubber compared with concrete flooring under the conditions of a commercial dairy farm. The study was conducted in an organic dairy herd with free-stall housing. Floor preference was tested on groups of standing cows in a $120-\mathrm{m}^{2}$ holding pen before milking, and $1 \mathrm{yr}$ later on a $12-\times 3-\mathrm{m}$ walkway. The holding pen and the walkway were divided lengthwise into 2 identical sections. Two types of solid rubber mats (soft and extra soft) were tested against solid concrete in the holding pen. Slatted and solid rubber mats were tested against slatted concrete in the walkway. Each floor type was tested over $4 \mathrm{~d}$ on the left side and $4 \mathrm{~d}$ on the right side of the holding pen and the walkway, respectively. Concrete flooring on both sides of the sections was tested as a control before the testing of different section materials. All observations of the distribution of cows in the sections were made from video recordings captured in association with the afternoon milking. The number of cows on each section was recorded approximately every $7 \mathrm{~min}$ in the holding pen, and continuously on the walkway. A significantly higher proportion of cows stood on the side with the soft and extra soft rubber mats $(65.1 \pm 2.7$ and $69.3 \pm 2.6 \%$, respectively, mean \pm SEM) compared with the control distribution when only the solid concrete was available $(50.9 \pm 3.9 \%)$. A significantly higher proportion of nonlame cows walked exclusively on the side with the slatted $(64.5 \pm 5.4 \%$, d 4$)$ or solid rubber mats $(68.2 \pm 5.1 \%$, d 4) compared with
\end{abstract}

Received December 21, 2006.

Accepted April 19, 2007.

${ }^{1}$ Corresponding author: Evgenij.Telezhenko@hmh.slu.se controls $(28.9 \pm 4.3 \%)$. Lame cows within a group of walking cows did not show a higher preference for soft flooring as distinct as nonlame cows $(52.7 \pm 6.9$ and $59.4 \pm 6.2 \%$ for the solid and slatted rubber mats, respectively, at $\mathrm{d} 4 \mathrm{vs} .40 .3 \pm 6.2 \%$ for control), presumably because of competition with other, higher ranked cows. It was concluded that the majority of cows preferred to walk and stand on soft rubber rather than on concrete flooring.

Key words: dairy cattle, preference test, rubber mat, lameness

\section{INTRODUCTION}

The use of free stalls with concrete passageways for dairy cattle is steadily increasing in Nordic countries (Raussi, 2003). Yet, this type of housing has been associated with more claw lesions and lameness compared with tie stalls (Bergsten and Herlin, 1996). Lameness is an important indicator of pain, and therefore, of poor animal welfare (Whay et al., 1997). Hard, abrasive, or slippery concrete floors on walkways of free-stall barns may contribute to trauma and predispose to claw horn lesions (Cook et al., 2004), and the use of rubber mats on the walkways improves locomotion comfort and reduces the risk of injury (Telezhenko and Bergsten, 2005; Rushen and de Passillé, 2006).

The softness of the lying areas has always been the main issue regarding cow comfort (Tucker and Weary, 2001), but more attention is now being paid to cow comfort in the walking areas (Rushen and de Passillé, 2006). Besides providing better comfort, it is assumed that elastic rubber mats in the walking areas may have favorable effects on claw health due to decreased pressure on the claw soles (Cook et al., 2004). Studies of a computer-based finite element model of a bovine claw showed that the maximum pressure peaks were 3 times higher on a hard surface than on a soft one (Hinterhofer et al., 2005). In tie stalls, rubber mats significantly reduced sole lesions compared with concrete (Bergsten and Frank, 1996). The effect of rubber flooring on claw health in walking areas for loose-housed cattle was widely discussed, but there was no strong evidence that 
rubber mats have a significant effect on reducing claw lesions (Vokey et al., 2001; Vanegas et al., 2006). Nevertheless, many dairy farms with free-stall housing currently use rubber flooring in selected areas where cows spend a considerable amount of time standing or walking.

Given the possible beneficial effect of rubber flooring on claw health (Benz, 2002), should we expect that cows given only partial access to rubber covering would instantly prefer to walk and stand on the rubber mats? Answering this question requires the use of a preference or choice test. Such a test can increase our understanding of the requirements of animals, and thus how their welfare might be improved (Fraser and Matthews, 1997).

The objective of this study was to investigate whether dairy cows prefer to stand and walk on rubber mats rather than concrete floor under the conditions of a normal commercial dairy farm.

\section{MATERIALS AND METHODS}

\section{Housing, Animals, and Management}

The study was carried out on a private, commercial, organic dairy farm in the southwest of Sweden (Västra Götaland county). Cows were housed in a 9-yr-old uninsulated free-stall building made of self-supporting steel roof trusses, with automatically controlled climate ventilation. The $2 \times 3$ row design had feed stalls along the common feeding platform, and free stalls equipped with rubber mats (UBO, Barneveld, the Netherlands). The slatted flooring consisted of single, 125-mm-wide prestressed concrete slats separated by $40-\mathrm{mm}$-wide profiles (void ratio of $24 \%$ ). The free-stall barn was connected to the insulated milking center, which included a $120-\mathrm{m}^{2}$ lengthwise grooved concrete holding pen with $5 \%$ slope, and a $2 \times 12$ parallel parlor (Index 90, Fullwood Ltd., Shropshire, UK), with return alleys on both sides of the holding pen (Figure 1).

During the study, the herd had approximately 280 milking cows, comprising Swedish Red (39\%), Swedish Holsteins (52\%), and cows of other breeds and crossbreeds (9\%), with an average ECM production over 2 yr of $9,300 \mathrm{~kg}$ for $305 \mathrm{~d}$. The cows were separated into 3 management groups: 2 high-producing $(\mathrm{n}=65$ and $95)$ and 1 middle-producing $(\mathrm{n}=120)$ group. The management groups were selected by the farm manager, based mainly on the stage of lactation (first-calving heifers were mixed with older cows) and were kept together during the time of observations. Cows were milked twice daily. All cows were kept under similar management conditions; the young stock were reared on deep-bedded straw packs with a scraped solid con- crete feeding alley, and all animals were grazed from May to September.

Rubber mats of different qualities (Gummiwerk Kraiburg Elastik, Tittmoning, Germany) were used to modify the existing solid and slatted concrete floors of the different test sections. The soft rubber mats (KEN; 20 mm thick) and extra soft rubber mats (KSL; $30 \mathrm{~mm}$ thick) were used to study standing preferences (experiment 1), and slatted rubber mats (KURA-S) and solid rubber mats (KURA-P; both $22 \mathrm{~mm}$ thick) were used to study walking preferences (experiment 2). The KURA-S rubber mats had perforated slots $(123 \times 38 \mathrm{~mm})$ with a void ratio of approximately $15 \%$, but were otherwise identical to the KURA-P mats. Both KURA-S and KURA-P mats had studded profiles (5-mm studs) on the bottom side of the mat, to provide extra softness. The KEN mats had a design and softness similar to the KURA mats, whereas the KSL mats had larger studs on the bottom $(15 \mathrm{~mm})$ and consequently greater softness.

\section{Study Design}

Experiment 1. Floor preference for standing was tested in the holding pen before the cows entered the milking parlor. The holding pen was divided lengthwise into 2 sections (Figure 1), identical regarding size and design and placement of waterers, but the right side of the parlor was connected with the entrance to the calving pens and was oriented to the north. Before comparing the different flooring materials, the control data, using concrete in both sections, were counted as the proportion of cows standing first on the right side of the holding pen and then on the left side, during $2 \mathrm{~d}$ of observation per side (Table 1). The following floor materials were then tested: KSL vs. KEN, KEN vs. solid concrete, and KSL vs. solid concrete. Every alternative was tested for $4 \mathrm{~d}$ on each side of the holding pen (Table 1). All observations of cow distribution in the sections were made from video recordings, captured by a video camera positioned $3.5 \mathrm{~m}$ above the holding pen, in association with the afternoon milking. Because of twice-daily milking, the cows had actual contacts twice a day with each floor combination. Because observations were made only once daily, the recording of cow distribution was carried out at first, third, fifth, and seventh contact with the particular floor on the particular side of the holding pen. At every shift of the milking side in the milking parlor, the number of animals in the holding pen was reduced by 12 ; the number of cows standing in each section was counted 5 min after this shift had been made. That resulted in an observation approximately every $7 \mathrm{~min}$. A new management group was introduced after the holding pen was emptied sequentially until the entire herd was milked. The distri- 


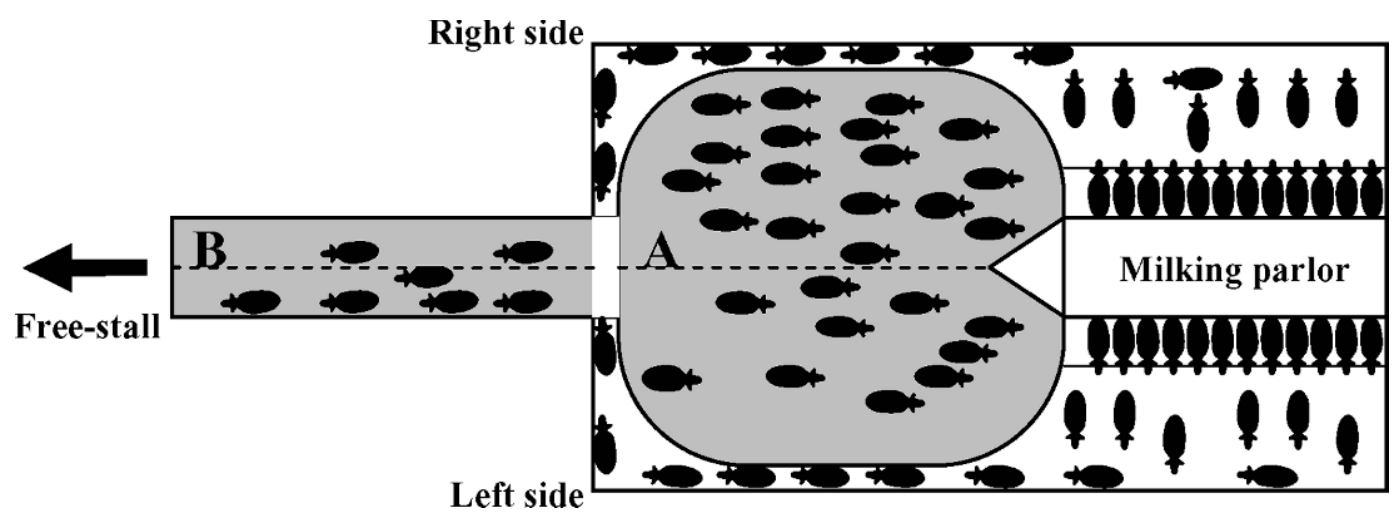

Figure 1. Design of the milking area. A management group of cows went through the walkway to the holding pen (A), where it was locked in and directed to the milking parlor by the herdsmen. After milking, 12 cows left each side of the parlor and walked freely back to the free-stall area. The dotted line shows the division of "test" and "opposite" sides in the holding pen and walkway (B), respectively.

bution of cows between sections was observed for the entire herd; however, only observations with more than $3.2 \mathrm{~m}^{2}$ of free space per cow within the holding pen were used for the analysis, and so recordings of animal distribution were started with approximately 40 animals in the holding pen for each management group. This cut-off point for stocking density was chosen to give a theoretical possibility of all the cows standing in the same flooring section in the holding pen. Because the number of cows within a group was not always divisible by 12 , the number of observations varied from 3 to 4 observations per management group and day.

The average proportions over multiple observations per day and management group were calculated and used for the subsequent analysis.

Experiment 2. Experiment 2 was conducted $1 \mathrm{yr}$ after experiment 1 . Walking preference with the different floorings was tested on the $12-\times 3$-m walkway as the cows left the milking parlor (Figure 1). Only cows from the 2 high-producing management groups ( $\mathrm{n}=$ 160) were included in the experiment, because they used the whole length of the walkway on their way to the free-stalls. The walkway was divided lengthwise into 2 equal parts, with no differences between sides or surroundings other than the geographical orientation. The following floor materials were tested: KURA-S vs. slatted concrete, KURA-P vs. slatted concrete, and KURA-P vs. KURA-S. Each flooring material was tested for $4 \mathrm{~d}$ on each side of the walkway (Table 1). A video camera was placed $4 \mathrm{~m}$ above the walkway, and the positions of the cows were recorded continuously during their free passage through the walkway after the afternoon milking. The number of observed contacts with a particular floor on the particular side was the same as described for experiment 1 . The traffic flow was approximately 70 cows/h.

The floor choices during walking were characterized as follows:

1) Walking on the test side (WTS)—-the proportion of cows walking exclusively on the test side from the beginning to the end of the walkway;

Table 1. Experimental schedule for experiments 1 and $2^{1}$

\begin{tabular}{|c|c|c|c|c|}
\hline \multirow{2}{*}{$\begin{array}{l}\text { Days of } \\
\text { experiment }\end{array}$} & \multicolumn{2}{|c|}{$\begin{array}{l}\text { Experiment } 1 \\
\text { (holding pen) }\end{array}$} & \multicolumn{2}{|c|}{$\begin{array}{c}\text { Experiment } 2 \\
\text { (walkway) }\end{array}$} \\
\hline & Floor left & Floor right & Floor left & Floor right \\
\hline $1-4$ & Solid concrete & Solid concrete & Slatted concrete & Slatted concrete \\
\hline $5-8$ & Soft rubber & Extra soft rubber & Slatted rubber & Solid rubber \\
\hline $9-12$ & Extra soft rubber & Soft rubber & Solid rubber & Slatted rubber \\
\hline $13-16$ & Extra soft rubber & Solid concrete & Solid rubber & Slatted concrete \\
\hline $17-20$ & Solid concrete & Soft rubber & Slatted concrete & Slatted rubber \\
\hline $21-24$ & Soft rubber & Solid concrete & Slatted rubber & Slatted concrete \\
\hline $25-28$ & Solid concrete & Extra soft rubber & Slatted concrete & Solid rubber \\
\hline
\end{tabular}

\footnotetext{
${ }^{1}$ Experiment 2 was carried out 1 yr after experiment 1, and the rubber mats were taken away from the holding pen immediately after experiment 1 was finished.

${ }^{2}$ The records were made at first, third, fifth, and seventh contact with a particular floor on a particular side (the first contact for the rubber floorings was then omitted from the analyses).
} 
2) Walking on the opposite side (WOS) - the proportion of cows walking exclusively on the opposite side from the beginning to the end of the walkway;

3) Changing to the test side (CTS) - the proportion of cows initially walking on the opposite side, but changing to the test side;

4) Changing to the opposite side (COS) - the proportion of cows initially walking on the test side, but changing to the opposite side.

Data on cows changing side twice was recorded, but was omitted from the subsequent analysis due to its low occurrence. Observations of cow allocation in which any interaction with personnel occurred were omitted.

The "test side" was the side covered with rubber mats when compared with concrete floor, and the side covered with solid rubber mats when compared with slatted rubber mats. For the control data, the right side of the walkway was considered as the test side for the first 2 $\mathrm{d}$, and the left side for the following $2 \mathrm{~d}$.

Occasionally, some cows passed along the walkway alone, that is, with no other cow on the walkway in front or behind them. The floor choices of these "single" cows were recorded separately in the same manner. Lame cows were identified during every observation, and their floor choice was recorded separately. Only cows with moderate and severe lameness (i.e., visible gait asymmetry) were considered lame. Across all the days of observation, about $17 \%$ of the cows were categorized as lame.

\section{Statistical Analysis}

The analyses of cow preference were carried out on a group level. The first day of observation of each floor section on each side was omitted from the analysis in both experiments due to possible carryover effects. The proportions of cows standing (experiment 1 ) or walking (experiment 2) on the relevant side were transformed by arcsine of square root of the proportion for the variance stabilizing (Dohoo et al., 2003). A repeated-measures ANOVA was used to analyze the transformed data in both experiments (PROC MIXED procedure; SAS 8.02, SAS Institute, 2003).

The model for experiment 1 included the following sources of variation: the effect of floor combination (extra soft vs. soft, soft vs. concrete, extra soft vs. concrete, and concrete vs. concrete; $\mathrm{df}=3$ ); the effect of the side of the holding pen $(\mathrm{df}=1)$; the effect of the number of contacts with a floor on the same side of the holding pen ( $\mathrm{df}=2)$; and the effect of the management group to which the cows belonged (defined as a subject in the model, $d f=2$ ). Because the proportion of cows standing on a particular side might be based on different num- bers of observations within each group and day, the data were weighted by the number of observations for each day and group.

Due to a significant interaction between floor and number of contacts with the floor in experiment 1 , the effect of floor was built as 10 categories: control observations and interaction term between floor combination and the number of the contact ( $\mathrm{df}=9$ ). Other effects in the model were the effect of the side of the walkway $(\mathrm{df}=1)$; the effect of cows walking alone or together with other animals $(\mathrm{df}=1)$; and the effect of the management group to which the cows belonged (defined as a subject in the model, $d f=1$ ). Again, as the proportion of cows walking on a particular side might be based on observations of different numbers of animals within each group and day, the data were weighted by the number of observed animals for each group and day. There was a negative correlation between the distributions of lame and nonlame cows $(\mathrm{r}=-0.19 ; P<0.05)$; therefore, to reduce the risk of type II error (Sokal and Rohlf, 1995), these 2 subgroups were analyzed separately using the same model. The other possible interactions were tested in both models, but were omitted because of their nonsignificance. The first-order autoregressive correlation structure for the management group within a tested floor combination and side was used for models in both experiments. The analyses of residuals for models of both experiments revealed no significant violation of the assumptions of normality and homoscedasticity. Multiple comparisons of the least squares means for "floor combination" (experiment 1) and "floor combination $\times$ number of contact" (experiment 2 ) with the control observations were performed using Dunnett adjustment (Dunnett's 2-tailed $t$-test). The differences were considered significant at $P<0.05 ; P$ values at $P \leq 0.1$ were considered as a tendency.

\section{RESULTS}

\section{Experiment 1: Preference for Standing on Different Floorings}

The proportion of cows standing on either of the rubber mats was significantly higher than the control level (Figure 2). There was a tendency for cows to prefer extra soft rubber mats over soft rubber mats. There was no significant effect of the number of contacts with a particular flooring $(P=0.51, F=0.69, \mathrm{df}=2)$ and no significant interaction between the number of contacts and a particular flooring $(P=0.83, F=0.42, \mathrm{df}=5)$.

The analysis revealed a tendency toward an effect of side of the holding pen $(P=0.08, F=3.14, \mathrm{df}=1)$. Cows tended to stand more on the right side of the holding pen, which was the side connected to the entrance to the calving section, and the difference due to side (about 


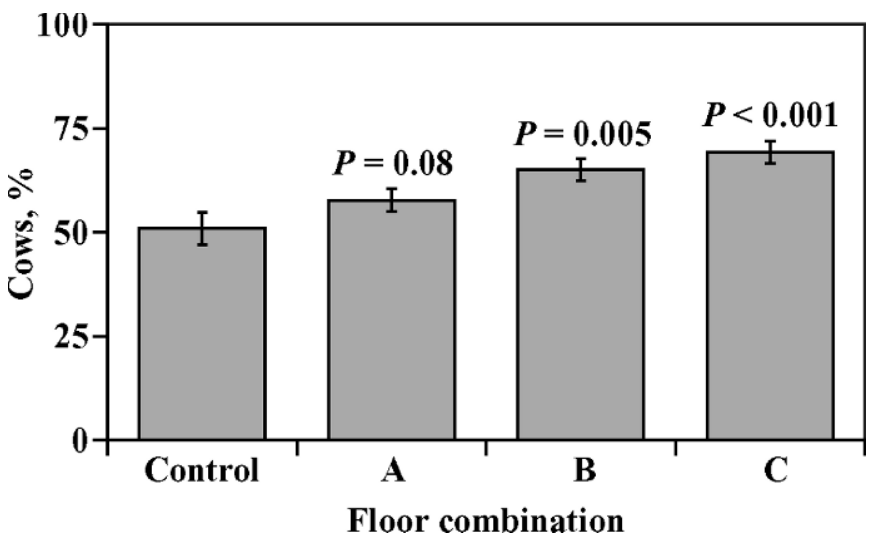

Figure 2. Distribution of cows between different floorings in the holding pen: $\mathrm{A}=$ extra soft rubber mats vs. soft rubber mats; $\mathrm{B}=$ soft rubber mats vs. solid concrete; $\mathrm{C}=$ extra soft rubber mats vs. solid concrete. Average percentage for all recorded days $( \pm \mathrm{SEM})$, comparisons with control (solid concrete vs. solid concrete), Dunnett's 2 -tailed $t$-test.

10\%) remained more or less constant across all the floor combination tests. No interaction effect was found between floor combination and side.

\section{Experiment 2: Preference for Walking on Different Floorings}

Nonlame Cows. When the rubber mats were tested against concrete floor, the proportion of WTS was significantly higher than the control level, and increased gradually with time of observation on the same side (Figure 3). There was a drop in the proportion of cows walking on the rubber flooring when it was switched to the opposite side (and so the first contact was not used in the analysis). When the solid and slatted rubber mats were tested, the proportion of WTS increased significantly up to the fifth contact, but somewhat decreased at the seventh contact; this did not differ significantly from the control level.

The proportion of COS was significantly lower than the control level for all categories except when solid rubber was compared with slatted rubber at the third contact. The proportion of CTS did not differ significantly from the control observations for any floor.

The effect of side was significant for all of the 4 categories of animal distribution (WTS: $P=0.003, F=9.8$, $\mathrm{df}=1$; WOS: $P<0.001, F=26.9, \mathrm{df}=1$; CTS: $P=0.002$, $F=11.1, \mathrm{df}=1$; COS: $P=0.02, F=5.94, \mathrm{df}=1$ ). The animals preferred walking on the left side of the walkway. No significant interaction was found between side and floor combination.

The proportion of cows walking on the test side was greater in cows walking alone than in cows walking within a group of herd mates $(P=0.008, F=7.57$, $\mathrm{df}=1)$. The proportion of COS decreased if the animals walked alone $(P=0.01, F=8.2, \mathrm{df}=1)$. The presence of more than 1 cow in the walkway did not have a significant effect on other choices along with interactions with floor combination.

Lame Cows. Among the lame cows, the floor combination of solid and slatted rubber mats did not show any significant effect on floor choice. When the slatted rubber was tested against slatted concrete, the proportion of WTS decreased slightly at the third contact compared with the control level (Figure 4). The proportion increased gradually thereafter, and became significantly higher only at the seventh contact with the floorings. A similar pattern was observed when solid rubber was tested against slatted concrete floor (Figure 4).

The proportion of COS remained at the same level as the control when solid and slatted rubber were tested, but decreased significantly when rubber mats were compared with concrete. The CTS and WOS proportions for lame cows did not differ significantly from the control level across any floor combination.

The proportion of lame cows was more or less constant during the observation period. No significant difference in proportion of lame cows was found between the days when the entire floor was covered with rubber and the days when only concrete was tested. In lame animals, the effect of side was significant for WTS ( $P$ $<0.001, F=43.5$, df $=1)$, WOS $(P<0.001, F=14.9$, $\mathrm{df}=1), \mathrm{CTS}(P<0.001, \mathrm{~F}=32.2, \mathrm{df}=1)$ and $\operatorname{COS}(P=$ $0.005, \mathrm{~F}=8.2, \mathrm{df}=1)$. Lame animals preferred to walk on the right side of the walkway, but there was no significant interaction between side and floor combination.

The proportion of lame cows walking alone on the test side tended to be larger than the proportion of cows walking together with other animals $(P=0.075, F=$ $3.26, \mathrm{df}=1$ ). The proportion of COS for lame cows was lower if the animals walked alone $(P=0.04, F=4.2$, $\mathrm{df}=1$ ). Other floor section choices were not significantly affected by the presence of other animals on the walkway.

\section{DISCUSSION}

The majority of cows preferred to walk and stand on soft rubber flooring rather than on concrete floors. The cows showed a slightly higher preference for walking on solid rather than slatted rubber mats, and a slight tendency to prefer standing on extra soft rubber mats. Yet, lame cows within a group apparently did not have a greater preference than nonlame cows for soft flooring.

The preference tests in the present study were carried out under conditions of "normal cow life" in a commercial dairy herd with free-stall housing. The complexity 
a)

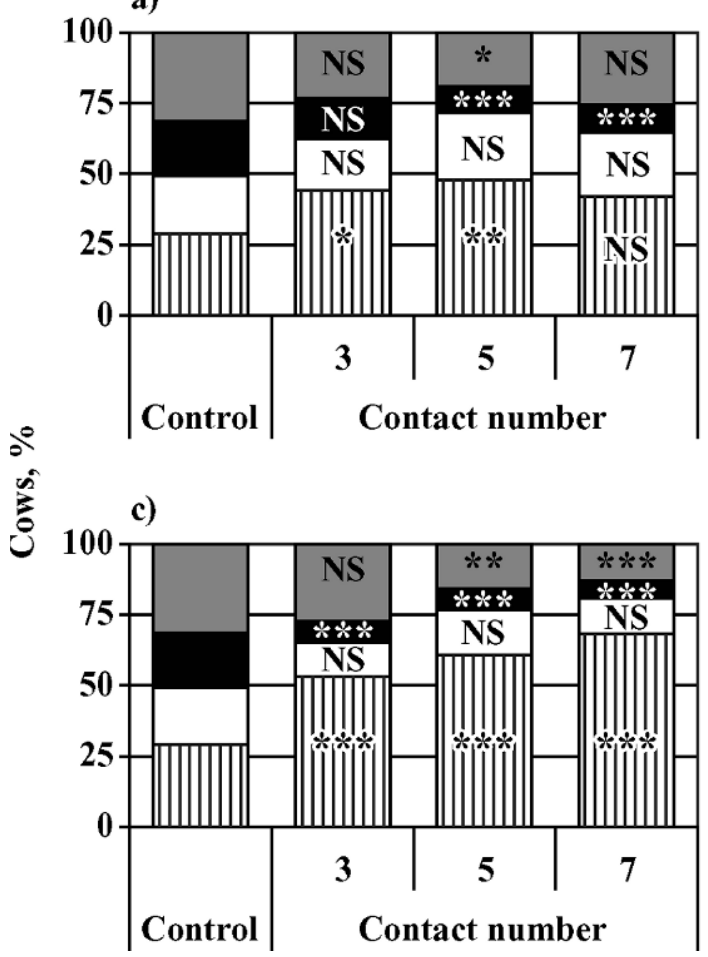

b)

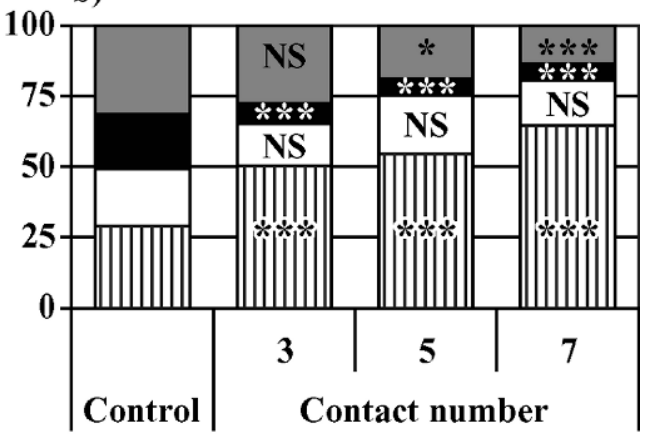

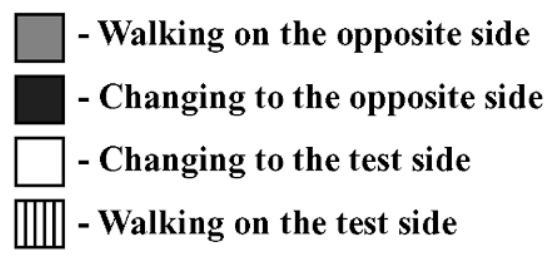

Figure 3. Distribution of nonlame cows when passing along the walkway with different floorings (right and left side are pooled). The floor combinations are a) solid rubber mats (test side) vs. slatted rubber mats (opposite side); b) slatted rubber mats (test side) vs. slatted concrete (opposite side); c) solid rubber mats (test side) vs. slatted concrete (opposite side). The significance shown within each allocation is the result of least squares means multiple comparisons (Dunnett's 2 -tailed $t$-test) with control (slatted concrete vs. slatted concrete); $* * * P$ $<0.001, * * P<0.01,{ }^{*} P<0.05$, NS $=P>0.05$.

of relationships between cows within a herd makes it difficult to evaluate correlations between individuals within a group. The cow is a social animal that may follow herd mates when choosing which flooring to walk on, resulting in a positive correlation between individuals. At the same time, competition for limited space could result in a negative correlation between the observed individuals. To secure reliable conclusions we analyzed the data on a group level, which resulted in a conservative test (Iason and Elston, 2002).

The preference tests are sensitive to the conditions under which the animals were reared, but it was demonstrated that previous experience would not necessarily play a crucial role in the choices an animal makes (Dawkins, 1983). Nevertheless, the animals in this study were given a short time ( $8 \mathrm{~d}$ or 16 contacts) to become accustomed to the rubber flooring at the beginning of the experiments, together with testing preference between different types of the rubber mats.

In experiment 1 , the cows in the holding pen seemed to need a greater stimulus to move, because almost every position change between the floorings seemed associated with personnel moving animals to the parlor for milking. Furthermore, the preference for the softer flooring in experiment 1 was not dependent on the number of contacts with a particular floor position. The explanation could be that cows already standing on the softer flooring had a higher willingness to continue to stay there than those on the opposite (harder) side. We could not identify lame cows during experiment 1 , and the possible latent effect of lameness is present in the results. The preferences were based on observations of the holding pen when at lower stocking density, and it was quite likely that most of the lame cows were still in the holding pen, because lame cows often enter the parlor late (Hassall et al., 1993). It is difficult to judge how a higher proportion of lame cows would affect the group preference for soft flooring. It is possible that lame cows had stronger motivation to stand on the soft flooring, but the negative correlation between the distributions of lame and nonlame cows in experiment 2 (when healthy cows walked on the test floor, it was less likely that lame cows walked there) suggests that lame cows may avoid the rubber flooring because of competition with other cows.

Experiment 2 was motivated by the difficulty of appreciating the effects of lameness and human interference on the flooring preferences in experiment 1 . In 
a)

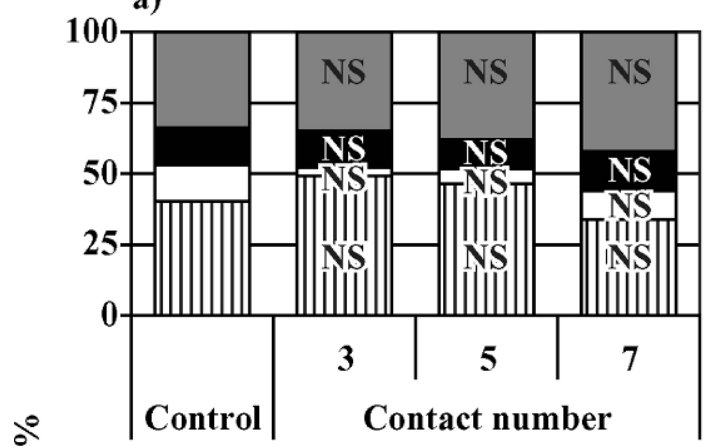

c)

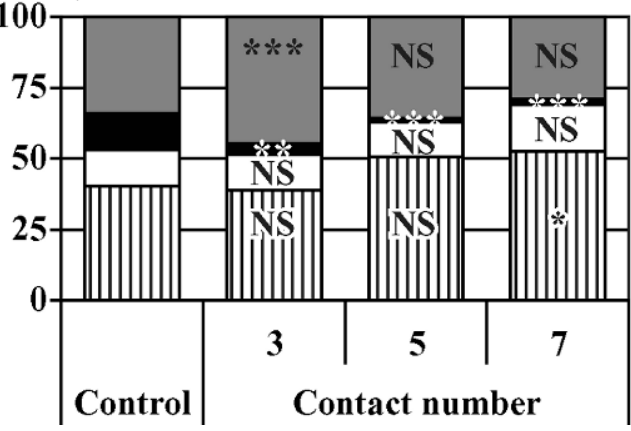

b)

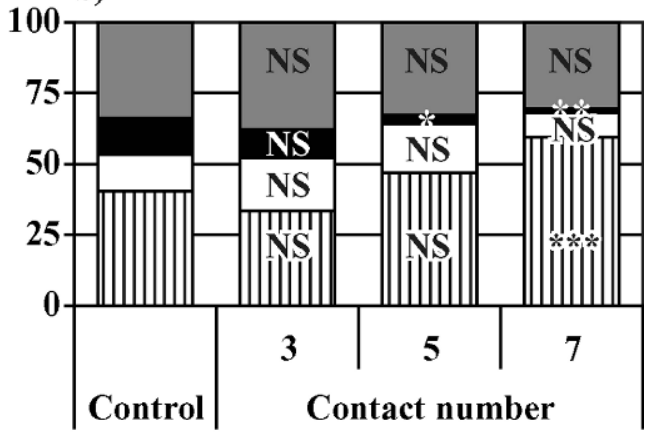

Figure 4. Distribution of lame cows when passing along the walkway with different floorings (right and left side are pooled). The floor combinations are a) solid rubber mats (test side) vs. slatted rubber mats (opposite side); b) slatted rubber mats (test side) vs. slatted concrete (opposite side); c) solid rubber mats (test side) vs. slatted concrete (opposite side). The significance shown within each allocation is the result of least squares means multiple comparisons (Dunnett's 2 -tailed $t$-test) with control (slatted concrete vs. slatted concrete); $* * * P<0.001$, $* * P<0.01, * P<0.05$, NS $=P>0.05$.

experiment 2, cows walked freely, with motivation to move toward eating and resting areas; in this scenario, detection of lameness was possible. Because subtle lameness might be masked by the soft flooring (Telezhenko and Bergsten, 2005), we only categorized animals as lame if they had a very clear locomotion distortion that was visible even on the rubber mats.

The proportion of cows walking only on the rubber mats increased gradually during the $4 \mathrm{~d}$ of testing on the same side. In the case of nonlame cows, the application of slatted rubber mats resulted in a $25 \%$ increase in the proportion of cows walking on the same side at the seventh contact. Use of solid rubber mats at the seventh contact caused a $30 \%$ increase. Dairy cows often persist in their choice of a particular side of milking parlor (Paranhos da Costa and Broom, 2001). We could see that cows preferred a particular side of the walkway or the holding pen regardless of flooring. Once the cows got used to soft flooring on one side, they were reluctant to change their habits even when the flooring was shifted to the opposite side. During experiment 2, when rubber mats were switched to the other side after $4 \mathrm{~d}$, at first the majority of cows continued to walk on the side that had been floored with rubber, a result in con- cordance with a study by Grandin et al. (1994). Observations during the first contact with the test flooring were therefore omitted from the analysis due to the abovementioned carryover effect. Nevertheless, the carryover effect did not disappear entirely even at the third and fifth contact, because the proportion of cows walking on the rubber mats on the "new" side increased progressively, in the same way as during the testing on the first side. The choice for soft flooring in lame cows became more distinct during the rubber mat exposure on the same side as well.

The social interactions among the animals affected their preferences for a particular floor. When cows walked alone through the walkway (experiment 2), the proportion of those walking on the rubber mats was higher than when the cows walked in a group with other cows. The explanation for this could be that in those cases when cows crowded onto the section with rubber flooring, other cows had to use the concrete side of the walkway, which would probably not be their primary choice under other conditions. It has been established that high-density husbandry causes increased social aggressiveness in cows (Bouissou et al., 2001). Therefore, the real preference of the cows for the softer 
floorings could have been underestimated when they were tested in groups. Yet, it was difficult to appreciate the real effect of the group, due to a lack of information regarding the previous experiences (and choices) of single walking animals.

The possible underestimation of the preference for soft flooring is especially plausible for the lame cows; they did not choose to walk on the soft side at the beginning of testing, most probably because of an increased proportion of other cows walking on that side. It was shown that cows with low social rank are more likely to become lame (Galindo and Broom, 2000). Presumably, the low-ranked lame cows in our study could not compete for softer flooring on the same terms as nonlame cows. Competition between cows for softer lying areas was reported by Herlin (1997), who described how cows displaced other animals significantly more from the most comfortable lying surfaces. Similar to nonlame cows, lame animals chose the side with rubber mats more often, and did not change to the side with concrete floor when there were no other cows on the walkway. However, even when walking alone, lame cows did not always choose the rubber mats. This might be explained by previous experience of some lame animals from earlier days of testing, when they were not allowed to walk on that side. The other reason for not choosing the rubber mats could be that the soft surface does not contribute to pain relief for certain types of lameness. Telezhenko and Bergsten (2005) showed decreased step asymmetry when lame cows walked on soft rubber mats; however, the origin of lameness was not established in that study.

When solid rubber mats were compared with slatted rubber mats (experiment 2), the proportion of cows choosing the solid part of the floor was somewhat larger. Cows may have a preference for solid flooring for the same reason they avoid crossing a "cattle guard." Albright and Arave (1997) showed that cattle avoided a cattle guard even if it was just painted across a paved road.

The probable underestimation of the preference for soft flooring in experiment 2 may have arisen from the short period of adaptation to the new floor placement, and the limited space of the walkway. An earlier demonstration of cow preference for a soft track surface by Gregory and Taylor (2002) showed that, when walking in groups, $96 \%$ of the cows preferred to walk on woodchips instead of on hard-core track.

Generally, it seems as if soft flooring is appreciated by dairy cows. Gregory and Taylor (2002) and Tucker et al. (2006) have shown that cows prefer soft flooring on areas other than the laying surface. Nonetheless, other aspects of welfare should be taken into account, such as effects of soft floorings on claw status. Kremer
(2006) criticized the use of rubber flooring, because it resulted in claw horn overgrowth due to the low abrasiveness of rubber mats. However, other studies showed that cows kept on rubber flooring showed not only decreased claw horn wear, but also decreased claw horn growth (Vanegas et al., 2006) and that net growth rate on rubber mats did not exceed that on concrete (Vokey et al., 2001). Another critical point concerning rubber matting may be when the addition of rubber mats in alleys in combination with compromised stall comfort increases standing time and may have a negative effect on claw health (Cook et al., 2004).

The results of the present study may be important for the deployment of new soft flooring materials. When rubber mats are used to partially cover the floor in freestall barns, lame cows (those that probably need the improved flooring most) may not be able to make use of this resource because of competition with nonlame, higher-ranked cows.

\section{CONCLUSIONS}

The shown preference for soft flooring indicates that softness of the walking areas is important for cow comfort. Still, under conditions of conventional dairy farming, the partial rubber covering of the walking and standing areas will not provide an opportunity for all animals to use this resource even with theoretically available space for all animals. The instant preference for a soft surface may not necessarily mean improved welfare in the long term. Further investigations are needed to assess the long-term effects of rubber flooring on the locomotion apparatus in cattle.

\section{ACKNOWLEDGMENTS}

This study forms part of the EU-funded framework 5 project "LAMECOW" (No. QLK5-CT-2002-00969). The provision of rubber mats by Gummiwerk KRAIBURG Elastik $\mathrm{GmbH}$ is greatly appreciated. The owners of Kårtorp säteri, and their foreman, Olof Andrén, are especially thanked for their cooperation and for giving us access to the dairy.

\section{REFERENCES}

Albright, J. L., and C. W. Arave. 1997. The Behaviour of Cattle. CAB International, Cambridge, UK.

Benz, B. 2002. Elastische Beläge für Betonspaltböden in Liegeboxenaufställen. PhD Diss. Universität Hohenheim, Hohenheim, Germany.

Bergsten, C., and B. Frank. 1996. Sole haemorrhages in tied primiparous cows as an indicator of periparturient laminitis: Effects of diet, flooring and season. Acta Vet. Scand. 37:383-394.

Bergsten, C., and A. H. Herlin. 1996. Sole haemorrhages and heel horn erosion in dairy cows: The influence of housing system on their prevalence and severity. Acta Vet. Scand. 37:395-408. 
Bouissou, M.-F., A. Boissy, P. Le Neindre, and I. Veissier. 2001. The social behaviour of cattle. Pages 113-145 in Social Behaviour in Farm Animals. L. J. Keeling and H. W. Gonyou, ed. CAB International, Wallingford, UK.

Cook, N. B., K. V. Nordlund, and G. R. Oetzel. 2004. Environmental influences on claw horn lesions associated with laminitis and subacute ruminal acidosis in dairy cows. J. Dairy Sci. 87(E Suppl.):E36-E46.

Dawkins, M. S. 1983. The current status of preference tests in the assessment of animal welfare. Pages 20-26 in Farm Animal Housing and Welfare. S. H. Baxter, M. R. Baxter, and J. A. C. MacCormack, ed. Martinus Nijhoff for CEC, Boston, MA.

Dohoo, I., W. Martin, and H. Stryhn. 2003. Veterinary Epidemiologic Research. AVC Inc., Charlottetown, Canada.

Fraser, D., and L. R. Matthews. 1997. Preference and motivation testing. Pages 159-173 in Animal Welfare. M. C. Appleby and B. O. Hughes, ed. CAB International, Wallingford, UK.

Galindo, F., and D. M. Broom. 2000. The relationships between social behaviour of dairy cows and the occurrence of lameness in three herds. Res. Vet. Sci. 69:75-79.

Grandin, T., K. G. Odde, D. N. Schutz, and L. M. Behrns. 1994. The reluctance of cattle to change a learned choice may confound preference tests. Appl. Anim. Behav. Sci. 39:21-28.

Gregory, N. G., and O. D. Taylor. 2002. Dairy cow preference for a soft track surface. N.Z. Vet. J. 50:83.

Hassall, S. A., W. R. Ward, and R. D. Murray. 1993. Effects of lameness on the behavior of cows during the summer. Vet. Rec. 132:578-580.

Herlin, A. H. 1997. Comparison of lying area surfaces for dairy cows by preference, hygiene and lying down behaviour. Swed. J. Agric. Res. 27:189-196.

Hinterhofer, C., J. C. Ferguson, V. Apprich, H. Haider, and C. Stanek. 2005. A finite element model of the bovine claw under static load for evaluation of different flooring conditions. N.Z. Vet. J. 53:165-170.
Iason, G. R., and D. A. Elston. 2002. Groups, individuals, efficiency and validity of statistical analyses. Appl. Anim. Behav. Sci. 75:261-265.

Kremer, P. 2006. Vergleich von Klauengesundheit, Milchleistung und Aktivität bei Kühen auf Betonspaltenboden und auf Spaltenboden mit elastischen Auflagen. PhD Diss. Ludwig-MaximiliansUniversität, München, Germany.

Paranhos da Costa, M. J. R., and D. M. Broom. 2001. Consistency of side choice in the milking parlour by Holstein-Friesian cows and its relationship with reactivity and milk yield. Appl. Anim. Behav. Sci. 70:177-186.

Raussi, S. 2003. Human-cattle interactions in group housing. Appl. Anim. Behav. Sci. 80:245-262.

Rushen, J., and A. M. de Passillé. 2006. Effects of roughness and compressibility of flooring on cow locomotion. J. Dairy Sci. 89:2965-2972.

SAS Institute. 2003. SAS for Windows, v8. SAS Institute Inc., Cary, NC.

Sokal, R. R., and F. J. Rohlf. 1995. Biometry. H. W. Freeman \& Co., New York, NY.

Telezhenko, E., and C. Bergsten. 2005. Influence of floor type on the locomotion of dairy cows. Appl. Anim. Behav. Sci. 93:183-197.

Tucker, C. B., and D. M. Weary. 2001. Cow comfort and stall design. Adv. Dairy Technol. 13:155-168.

Tucker, C. B., D. M. Weary, A. M. de Passillé, B. Campbell, and J. Rushen. 2006. Flooring in front of the feed bunk affects feeding behavior and use of freestalls by dairy cows. J. Dairy Sci. 89:2065-2071.

Vanegas, J., M. Overton, S. L. Berry, and W. M. Sischo. 2006. Effect of rubber flooring on claw health in lactating dairy cows housed in free-stall barns. J. Dairy Sci. 89:4251-4258.

Vokey, F. J., C. L. Guard, H. N. Erb, and D. M. Galton. 2001. Effects of alley and stall surfaces on indices of claw and leg health in dairy cattle housed in a free-stall barn. J. Dairy Sci. 84:2686-2699.

Whay, H. R., A. E. Waterman, and A. J. Webster. 1997. Associations between locomotion, claw lesions and nociceptive threshold in dairy heifers during the peri-partum period. Vet. J. 154:155-161. 